\title{
Performance Assessment of a Heat Recovery Unit Utilizing Turbine with Variable Inlet Guide Vanes Configuration for Application in Passenger Vehicles
}

\author{
Thaddaeus Julius', Tanimu Kogi Ibrahim¹, Emmanuel Okon Asukwo², \\ Ezeaku Ikeokwu Innocent ${ }^{3}$ \\ ${ }^{1}$ Federal University, Wukari, Nigeria \\ ${ }^{2}$ Nigeria Maritime University, Okerenkoko, Nigeria \\ ${ }^{3}$ Abia State University, Uturu, Nigeria \\ Email: thaddeus.julius@fuwukari.edu.ng
}

How to cite this paper: Julius, T., Ibrahim, T.K., Asukwo, E.O. and Innocent, E.I. (2021) Performance Assessment of a Heat Recovery Unit Utilizing Turbine with Variable Inlet Guide Vanes Configuration for Application in Passenger Vehicles. Journal of Power and Energy Engineering, 9, 120-133.

https://doi.org/10.4236/jpee.2021.95008

Received: February 22, 2021

Accepted: May 25, 2021

Published: May 28, 2021

Copyright $\odot 2021$ by author(s) and Scientific Research Publishing Inc. This work is licensed under the Creative Commons Attribution International License (CC BY 4.0).

http://creativecommons.org/licenses/by/4.0/

\begin{abstract}
This study explores the potentials of employing an Organic Rankine Cycle (ORC) system with variable inlet guide vanes (VIV) turbine geometry designed on a GT-Suite platform for effective exhaust heat recovery (EHR) application onboard passenger vehicles. The ORC model simulation was based on vehicle speed mode using R245fa as working fluid to assess the thermal performance of the ORC system when utilizing modified turbine geometry. Interestingly, the model achieved a very improved performance in contrast to the model without a modified turbine configuration. The results revealed the average $2.32 \mathrm{~kW}$ ORC net output, $4.93 \%$ thermal efficiency, $6.1 \%$ mechanical efficiency, and 5.0\% improved brake specific fuel consumption (BSFC) for the developed model. As determined by the performance indicators, these promising results from the model study show the prospect of EHR technology application in the transportation sector for reduction in exhaust emissions and fuel savings.
\end{abstract}

\section{Keywords}

Organic Rankine Cycle System, Variable Inlet Guide Vanes, Heat Recovery System, Mechanical Efficiency, Thermal Efficiency, Improved BSFC

\section{Introduction}

The transport industry is a huge contributor to challenges facing our environ- 
ment today, including air pollution and global warming [1]. These environmental issues are caused by exhaust gas release during fuel combustion in internal combustion engines (ICEs), which still thrives in most vehicle propulsions. Today's concerns about these negative impacts of combustion exhaust emissions; increasingly stringent emission regulations benchmarked on the quantity of $\mathrm{CO}_{2}$ expulsion from ICEs; and the need for sustainable and efficient deployment of fossil fuel resources in ICEs control the present trends of research and development (R \& D) in automobile industries. Therefore, recapturing some portion of the exergy in this waste heat stream, which otherwise is exhausted to the environment, not only mitigate exhaust emissions and their adverse effects but as well lead to thermal efficiency improvement of the model through the generation of additional power to augment the existing one without extra-fuel consumption by the IC engine [2].

Reports have that $27 \%$ of the main causes of greenhouse gas (GHG) release in the United States (US) is from the transport industry, and $41 \%$ of this proportion is from passenger cars and motorcycles as published by American Transportation Research Institution (ATRI) [3]. Furthermore, ERTRAC's R \& D forecast asserts that ICEs will still power more than $60 \%$ of new commercial vehicles in Europe up till 2040 owing to the need for energy density in some vehicle propulsions; thus, the expectation that ICEs will still control the transportation market for some time. Therefore, vehicle research trends will include ICE hybrids, extended configurations, waste heat recovery, and clean energy resources [4]. The exhausts released from ICEs of automobile vehicles comprise Nitrogen Oxide $\left(\mathrm{NO}_{\mathrm{x}}\right)$, which causes air pollution, Particulate Matter (PM), which causes breathing challenges in people with pre-existing conditions; and $\mathrm{CO}_{2}$, that is the major contributor to global warming threats. Technologies thus exist for reusing the thermal exergy in the exhaust of these vehicles such as Thermoelectric Generators, Turbo-compounding and ORC Systems being considered as a promising candidate technology for this application owing to its capability of operating effectively with limited heat sources, relatively increased thermal efficacy, and the simplicity of its architecture. ORC systems effectively achieve this heat recapturing by simply absorbing the exergy in the exhaust of these engines to evaporate the organic working fluid, that further expands to generate mechanical power, which is then converted to electricity employing an electric generator to supply power to the electrical appliances on board the vehicle or store in batteries for future use.

Recently, investigations on the deployment of ORC systems for EHR in vehicles are being reported in several online journals, and a few of such articles consulted are described in this project. In 2005, BMW's turbo steamer was reported as the first demonstration prototype system to use the Rankine cycle device to recover heat from exhaust stream to increase the automobile combustion process's efficiency. The cogeneration concept reduced fuel consumption in the 4-cylinder SI engine's stationary operating conditions by $10 \%$ [5]. Later, in 2007, Honda reported a Rankine cycle system installed in a hybrid vehicle for possible 
exhaust heat recovery from the engine. Testing the vehicle at $100 \mathrm{~km} / \mathrm{h}$ constant speed achieved a thermal efficacy boost of $13.2 \%$ [6]. However, the company in 2008 reported that it is not going ahead with production until higher efficiency is realized [7].

In 2011, steady-state testing was conducted on a TOYOTA 8A-FE gasoline engine operated at varying work environments. The ORC model achieved a thermal efficacy of $14.44 \%$ [8]. The second-generation turbo steamer of BMW has been again revealed in 2012 to have been modified to facilitate effective incorporation of the Rankine cycle module for EHR [9]. In 2013, Domingues et al. reported a Rankine cycle model simulation employing water, R123, and R245fa as working fluids. The study achieved an increase of $2.12 \%$ and $5.79 \%$ for thermal and mechanical efficiencies, respectively [10]. While in 2014, Abbe et al. studied an ORC system for EHR application in vehicles, which realised a 3.5\% boost in fuel savings [11].

In 2015, Rosset et al. studied the potentials of an ORC turbomachinery model for WHR applications in ICEs utilizing R1233zd as a working fluid. The system achieved $2.3 \mathrm{~kW}$ electrical output and a $10 \%$ boost in fuel savings [12]. Same year, Cipollone et al. proposed an ORC model for EHR applications in ICEs tested at different operating points employing R236fa. The model achieved cycle efficiency of 4.8\% [13]. A review of EHR systems from exhausts of passenger vehicles and trucks using ORC techniques was reported by Zhou et al. [14]. The integration of an ORC system to an engine model for EHR was reported by Arise et al. in 2016. The model achieved significant boost in fuel savings with $\mathrm{CO}_{2}$ reductions of $4 \%$ on standard driving cycles [15]. In 2016, the development of an ORC system for WHR from the exhausts of automobile engines was reported by Rongqi et al. using the Active Disturbance Rejection Control (ADRC) approach. The model works steadily and reliably with control error lower than $0.1 \%$ and fluctuation of superheating of less than $1^{\circ} \mathrm{C}$ relative to traditional ORC system [16].

In 2017, Galindo et al. carried out a 1D modelling of an ORC module designed with a swash-plate expander for EHR from a 2 L SI engine employing ethanol as working fluid. The model achieved an expander output of $800 \mathrm{~W}$, offering a potential of $2.5 \%$ improvement of fuel efficacy and a $23.5 \mathrm{~g} / \mathrm{kW}$ reduction in BSFC when operating at $120 \mathrm{~km} / \mathrm{hr}$ NEDC [17]. Investigations on the economic analysis of ORC application in the transportation sector were reported in 2017. The investigations revealed that ORC mass and volume must be reduced by $13 \%$ and $59 \%$, respectively, for trains, while higher reductions are required for vehicular applications [18] [19]. In 2017, Amin et al. studied the deployment of a WHR system to a hybrid electric vehicle using three different driving cycles. The model simulation achieved a significant decrease in the overall fuel use of the vehicle [20]. In same 2017, Zhao et al. designed a recuperative ORC module to compare its performances to a traditional ORC model as applied to EHR from vehicle engines. The study showed that cooling water temperature reduces with a boost in net output for the recuperative ORC to the traditional 
ORC. It also reveals that compared with basic ORC, the back pressure and engine performance are not affected when recuperation is added. However, more charged of refrigerant and longer response time are disadvantages [21].

In 2019, Yue et al. modelled an ORC system for EHR application in vehicles. The model achieved a maximum power output and fuel-saving rate of $14.7 \mathrm{~kW}$ and 0.23, respectively [22]. In same year, Volkswagen and MAN Diesel developers incorporated EHR systems to two of their conventional vehicles: Golf 7, 2-1 TFSI EA888, and Demo truck D2676 LF25 Euro VI, respectively. The models demonstrated a $75 \%$ evaporator efficacy and a $3 \%$ decrease in fuel use [23]. The feasibility and potentials of the EHR model for applications in long-haul trucks were reported in 2021. The numerical and experimental studies of the ORC model revealed an encouraging result with great feasibilities. The studies achieved $2.99 \mathrm{~kW}$ and $3.67 \mathrm{~kW}$ for net outputs achieved from numerical and experimental investigations, respectively [24] [25].

As evident from the reviewed literature, EHR in vehicles is being studied recently, and the technology is not in the market yet but still in the research stage, and more studies for improved performance and fuel savings are still anticipated. Therefore, investigating this ORC system equipped with a turbine utilizing variable inlet guide vanes (VIV) geometry running on vehicle speed presents another potential and predict real-life performance of the procedure as applied to onboard automobiles. There are scanty or no journal papers that report investigations of ORC system employing VIV modified turbine configuration and at the same time operating on vehicle speed mode, therefore, this research examines the performance of an ORC unit designed with modified turbine configuration and operating on vehicle speed mode for application in passenger vehicles.

\section{Methodology}

The engine model in this work is centred on a $1.25 \mathrm{~L}$ spark ignition engine with specifications presented in Table 1 [26]. The exhaust heat recovery (EHR) system was modelled on a GT-suite platform to examine the exhaust conditions and the energy recovery prospects of the model dependent on vehicle speeds mode, and the description of the model set up is given in Figure 1. The modelling of the system was performed on imposed speeds of $62,124,186$, and 248 $\mathrm{km} / \mathrm{hr}$ to as much as possible achieve a real-life performance scenario for eventual consideration in future development and the expression used in this project for converting the engine revolution to vehicle speed was obtained [27] and is described by Equation (1).

$$
k=d \times r \times 0.001885
$$

where, $k=$ kilometre per hour $(\mathrm{km} / \mathrm{hr}) d=$ wheel diameter $(\mathrm{cm}) r=$ revolution per minute (rpm).

The performance indicators examined in this work include engine BSFC, BMEP, ORC thermal performance, and VIV as tool for performance optimization as described subsequently. 


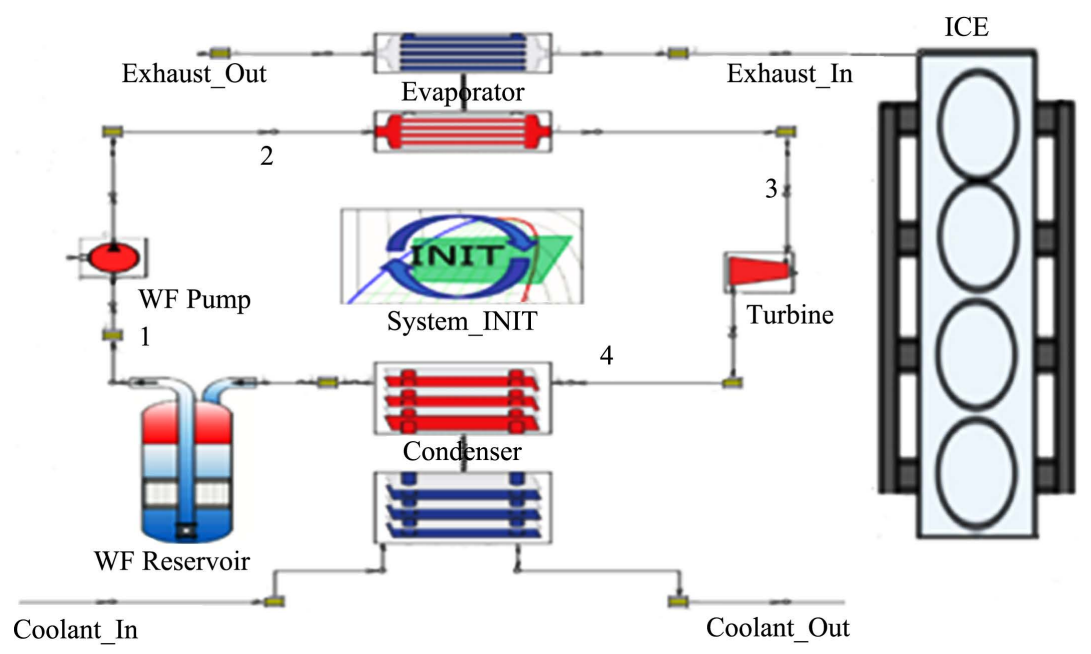

Figure 1. Diagram of the developed ORC model.

Table 1. 1.25 L Zetec-SE DHOC gasoline engine specifications [26].

\begin{tabular}{cc}
\hline ITEM & SPECIFICATION \\
\hline Model & ZETEC-SE DHOC \\
Displacement (l) & 1.25 \\
Stroke $(\mathrm{mm})$ & 71.9 \\
Bore $(\mathrm{mm})$ & 76.5 \\
Number of Cylinder & 4 \\
Number of Valves & 4 \\
Maximum Torque & 1100 Nm \\
Maximum Power & $60 \mathrm{~kW} @ 4000 \mathrm{rpm}$ \\
Fuel Type & Unleaded Gasoline
\end{tabular}

\subsection{Engine BSFC}

Brake Specific Fuel Consumption (BSFC) measures the engine's fuel to produce $1 \mathrm{~kW}$ of brake power per hour. The expression for evaluating this engine parameter is given as:

$$
\operatorname{BSFC}=\frac{\text { Fuel Flowrate }\left(\dot{m}_{f}\right)}{\text { Engine Power }\left(\dot{W}_{\text {Eng }}\right)}(\mathrm{g} / \mathrm{kW} \cdot \mathrm{hr})
$$

\subsection{BMEP}

Brake Mean Effective Pressure (BMEP) is a theoretical indicator that measures the effectiveness of an engine, and the expression for evaluating this indicator is given as:

$$
\mathrm{BMEP}=\frac{2 \pi \times T \times N_{R}}{V_{d}}(\mathrm{bar})
$$

where $V_{d}=$ swept volume, $T=$ torque, and $N_{R}=$ number of revolutions. 
In the ORC module, the EHR process was modelled employing R245fa as working fluid owing to its high performance and commonly used in ORC for ICE applications, and the working fluid from the reservoir is pressurized in the pump Process 1 - 2, then sent to the evaporator. The combustion heat in the exhaust stream vaporizes the high-pressure working fluid in the evaporator heat exchanger; Process 2 - 3 then expands to create mechanical power at the turbine's shaft, Process 3 - 4. Finally, the low-pressure working fluid exiting from the turbine condenses back to liquid in the condenser Process 4 - 1, and the cycle repeats.

\subsection{Optimization via VIV}

In optimizing the efficacy of the designed EHR system, the concept of VIV is to direct the flow at an optimum direction to the turbine rotor for improved energy extraction, a characteristic option only available to radial turbine over its axial counterpart. The attribute also allows the turbine to operate both as a small- or large-scale turbine, thereby enhancing efficacy and reducing the warm-up period. The turbine wheel extracts energy from the fluid flow and converts it to mechanical energy that produces electricity utilizing a generator at the other end of the turbine shaft. The VIV optimization procedure was modelled by employing the guide vanes position at $20 \%, 40 \%, 60 \%$, and $80 \%$ openings (Rack Positions) on the turbine stator.

\subsection{Performance Evaluation}

An outline of the equations governing the created ORC module used in evaluating the thermal effectiveness of the model is given as follows:

Heat input to the system via the evaporator

$$
\dot{Q}_{i n}=\dot{m}_{\text {exh }}\left(h_{\text {exh_in }}-h_{\text {exh_out }}\right)=\dot{m}_{W F}\left(h_{3}-h_{2}\right)
$$

where $\dot{m}_{e x h}=$ mass flowrate of exhaust gas, $\dot{m}_{w f}=$ mass flowrate of working fluid, $h_{\text {exh_in }}, h_{\text {exh } h_{\text {out }}}, h_{2}$ and $h_{3}$ are enthalpies of exhaust and working fluid as defined in Figure 1.

Heat is expelled from the system through the condenser.

$$
\dot{Q}_{\text {out }}=\dot{m}_{w} C p_{w} \Delta T_{w}
$$

where $\dot{m}_{W F}$ and $\dot{m}_{w}$ are working fluid and cooling water mass flowrates, $h_{4}$ and $h_{1}$ are enthalpies at the various points in Figure $1, C p_{w}$ is the specific heat capacity of the cooling water and $\Delta T_{w}$ is the change in temperature of the cooling water.

The electricity output available at the turbine is given as:

$$
\dot{W}_{\text {tur }}=\eta_{\text {mech }} \eta_{g e n} \dot{W}_{\text {tur }}-\frac{\dot{W}_{\text {elec }}}{\eta_{M}}
$$

where $\dot{W}_{\text {elec }}, \dot{W}_{\text {tur }}$ and $\dot{W}_{p}$ are electricity output, turbine power out and pump consumption, $\eta_{\text {mech }}, \eta_{\text {gen }}$ and $\eta_{M}$ are mechanical efficiency, generator efficiency and mechanical efficiency of the pump. 
The expression gives the electricity consumption by the pump:

$$
\dot{W}_{\text {elec }}=\dot{m}_{w f}\left(h_{2}-h_{1}\right)
$$

where $h_{1}$ and $h_{2}$ are the enthalpies of the working fluid in and out of the working fluid pump.

The ORC thermal efficiency is given as:

$$
\eta_{t h}=\frac{\dot{W}_{\text {tur }}-\dot{W}_{\text {elec }}}{\dot{Q}_{\text {in }}} \times 100
$$

The engine BSFC improvement from the ORC system is given as:

$$
\text { BSFC Improvement }=\frac{\text { Fuel Flowrate }}{\text { Engine Brake power }+\mathrm{ORC} \mathrm{Net}_{\mathrm{FIV} / \mathrm{IV}}}(\mathrm{g} / \mathrm{kW} \cdot \mathrm{hr})
$$

The expression employed in this study for evaluating the mechanical efficiency of the system is given by Equation (10).

$$
\eta_{\text {mech }}=\frac{\dot{W}_{\text {net }}}{\text { Brake Power }}
$$

\section{Results Discussions}

\subsection{Engine Model Performance}

This section provides the engine model effectiveness in forms of exhaust temperatures, exhaust mass flow rates, and engine BSFC from modelling the system on vehicle speed mode. The simulation was done at a cycle time of $1000 \mathrm{sec}$ in each case, and the corresponding exhaust conditions are used as input variables to the ORC loop, which investigates the ORC EHR potentials. Figure 2 presents the exhaust temperature distribution as realized in the engine model presented as functions of vehicle speed and BMEP. The model achieved exhaust temperature values ranging from $393^{\circ} \mathrm{C}$ to $796^{\circ} \mathrm{C}$ at vehicle speeds of 62 to $248 \mathrm{~km} / \mathrm{hr}$ and BMEP of 2 to 9.8 bar. This result reveals that the combustion exhaust temperature increases with increased engine speed and load; thus, the higher the operating vehicle speed, the better the available heat in the exhaust stream for recovering.

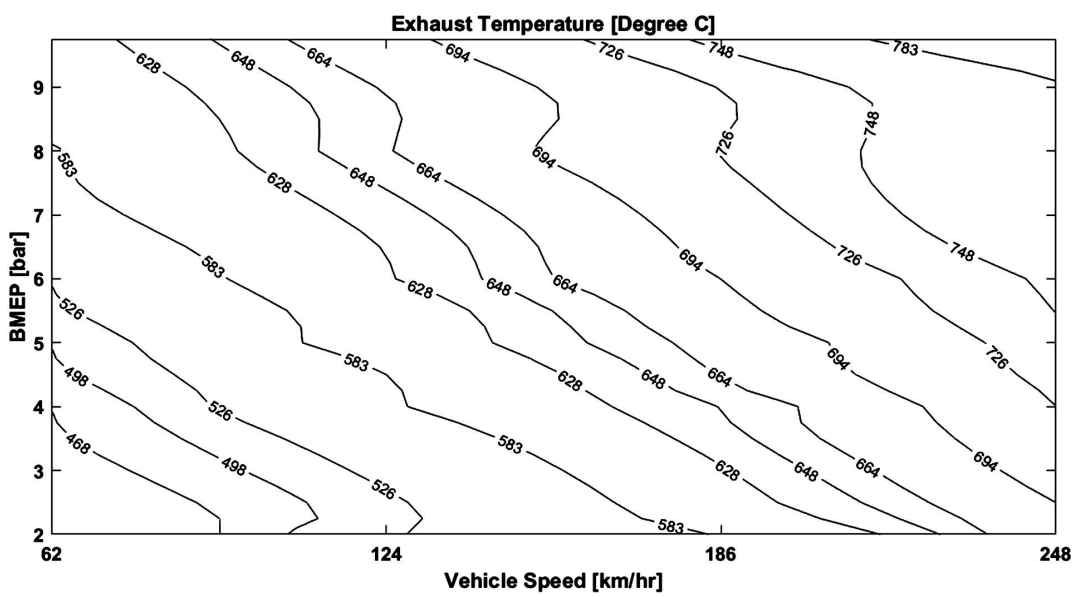

Figure 2. Exhaust temperature distribution. 
Figure 3 shows the flow rate distribution of the engine exhaust achieved from the model simulation. The mass flowrate another critical component used in assessing the exhaust feasibility of EHR units for automobile applications. The flowrates obtained in this case fall with 18 to $260 \mathrm{~kg} / \mathrm{hr}$. The flow rates result reveal that the higher the vehicle speed and load, the better the flow rates of the exhaust stream. Thus, when running at cruising speeds, one can be sure of a better effectiveness of the EHR unit.

As revealed in the journals consulted, only about $30 \%$ to $40 \%$ of the fuel content is converted to useful brake power during combustion, whereas the residual portion of the energy is expelled to the surrounding in the forms of exhaust and engine cooling systems. Figure 4 presents the relationship between the engine brake power and fuel energy lost via the exhaust stream, which is available for reuse. The model realized the average 10 to $32 \mathrm{~kW}$ engine brake power and 6 to $42 \mathrm{~kW}$ of available exergy in the exhaust stream. The findings show that both the brake power and exergy in the exhaust increase with increasing speed and load. Comparing the two parameters gained from the model, it is obvious that at higher vehicle speeds, around $200 \mathrm{~km} / \mathrm{h}$ above, the SI engine losses more of the fuel energy to the exhaust stream than the brake power for useful work.

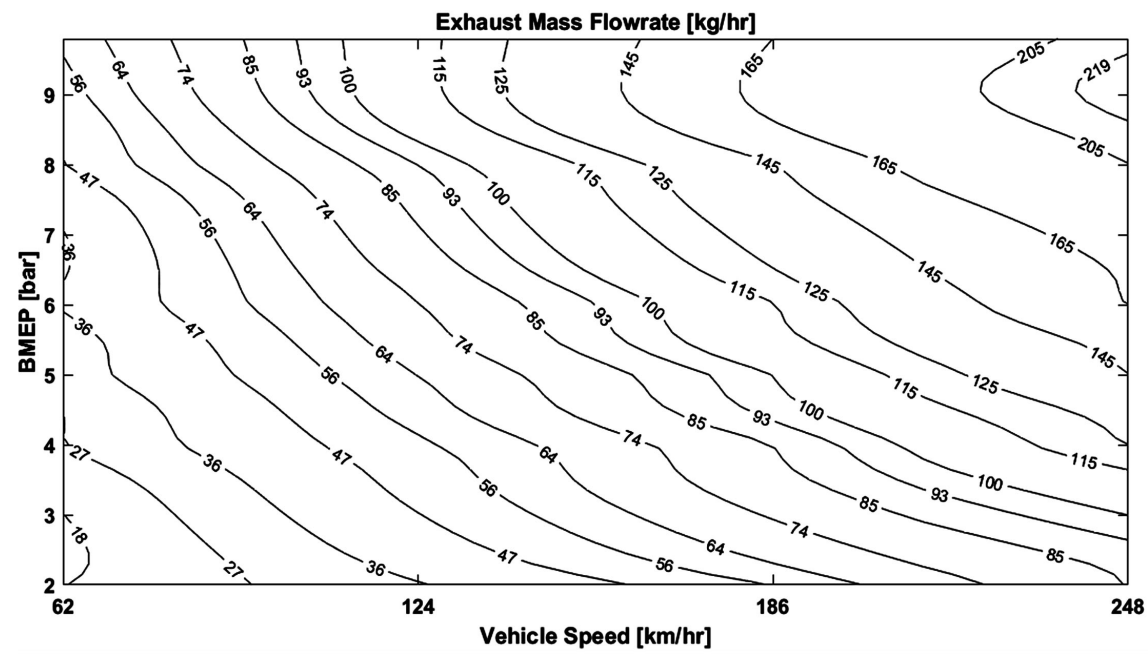

Figure 3. Exhaust mass flowrate distribution.

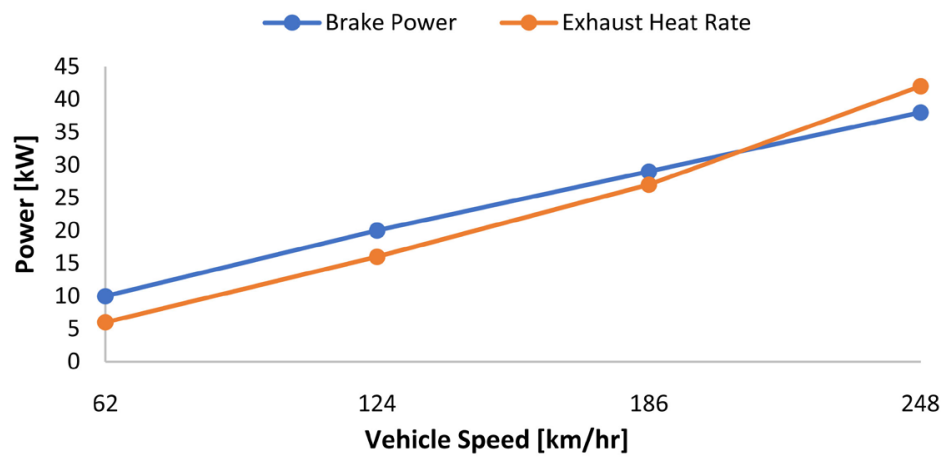

Figure 4. Engine brake power vs. power lost in exhaust. 


\subsection{Influence of VIV on the Performance of the EHR System}

The ORC unit was optimized employing a VIV turbine to determine the extent of this concept's impact on the effectiveness of the EHR unit relative to that with fixed inlet vanes (FIV) turbine. Figure 5 presents the BSFC improvements from the deployment of the ORC model using regular FIV and VIV turbines for EHR application in the passenger vehicle using a SI engine. The model achieved the best BSFC performances at $124 \mathrm{~km} / \mathrm{hr}$. The BSFC results realized in this project include $253 \mathrm{~g} / \mathrm{kW} \cdot \mathrm{hr}$ from the engine model and the BSFC improvement of 250 $\mathrm{g} / \mathrm{kW} \cdot \mathrm{hr}$ and $248 \mathrm{~g} / \mathrm{kW} \cdot \mathrm{hr}$ due to the deployment ORC system with FIV and VIV turbine configurations. The model demonstrates maximum BSFC improvement of $3.7 \%$ and $5.0 \%$ for the turboexpander with FIV and VIV, respectively.

Mechanical efficiency is another potential impact on the engine performance achieved from installing an EHR system.

Figure 6 compares the mechanical efficacy of the SI engine realized from modelling the ORC unit employing turbine with and without variable inlet guide vanes geometry for optimal flow direction. The results reveal mechanical efficiencies of $0.3 \%$ to $6.1 \%$ for the ORC model, employing a turbine using VIV as

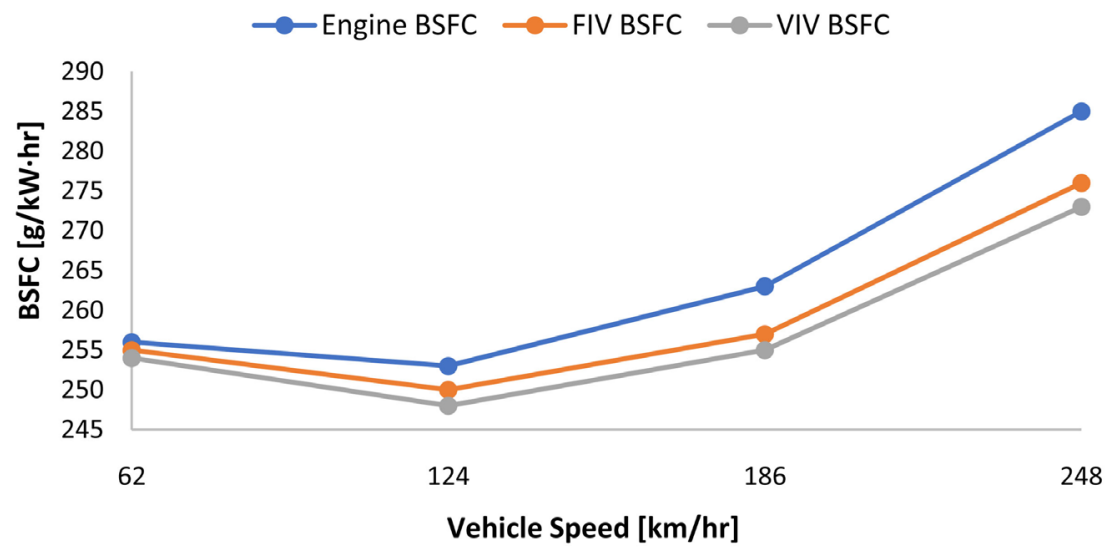

Figure 5. Comparison of BSFCs achieved due ORC system.

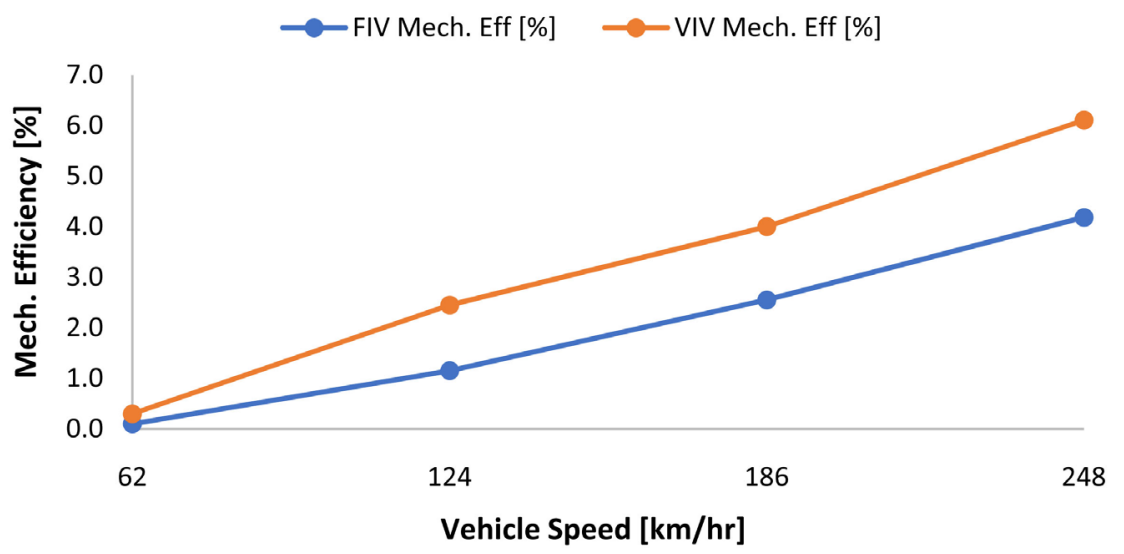

Figure 6. Mechanical efficiency due to ORC system. 
against $0.1 \%$ to $4.2 \%$ from the ORC model utilizing a fixed inlet guide vane configuration. The findings show an approximately $31 \%$ boost in mechanical efficacy of the system realized from an EHR system employing a turbine with a VIV stator configuration. The results also showed that the mechanical efficacy of the SI engine increases with increasing engine speed, as demonstrated in both cases.

\subsection{Thermal Effectiveness of the ORC System}

The effectiveness of the ORC model is measured in forms of power output, ORC net, and thermal efficacy of the system, all examined as a function of engine speed. Figure 7 describes the evolution of the ORC system's net output with increasing vehicle speeds as demonstrated by the EHR system utilizing turbines with and without variable inlet guide vanes. The results present 0 to $1.59 \mathrm{~kW}$ as net output realized from the ORC model utilizing turbine with modified inlet guide vanes, while the introduction of a turbine with variable inlet guide vanes achieved a net output of 0.03 to $2.32 \mathrm{~kW}$ corresponding to a maximum boost of about 0.31 when operating at vehicle speed of 62 to $248 \mathrm{~km} / \mathrm{h}$. The outcome shows that $0.73 \mathrm{~kW}$ can be achieved as an addition when the turbine with VIV stator geometry is employed for the expansion process.

Figure 8 presents the efficacies of the ORC model with and without modification of the turbine stator configurations. As observed in the previous performance indicators of the EHR system, the modified turbine geometry achieved better effectiveness of the ORC model with up to $4.93 \%$ cycle efficiency relative to $3.37 \%$ shown by the turbine without modified geometry. This result reveals a huge potential for implementing an EHR system with modified stator geometry in the transport industry for energy sustainability and emission control targets.

Furthermore, the variable inlet guide vanes configuration was modelled at different rack positions: $20 \%, 40 \%, 60 \%$, and $80 \%$ openings that would be automatically determined by the flow characteristic of the working fluid at the entrance of the turboexpander. Figure 9 shows the thermal efficacy realized by the various guide vanes positions of the turboexpander geometry as achieved in this study. The results reveal that the stator configuration at 0.4 vanes position

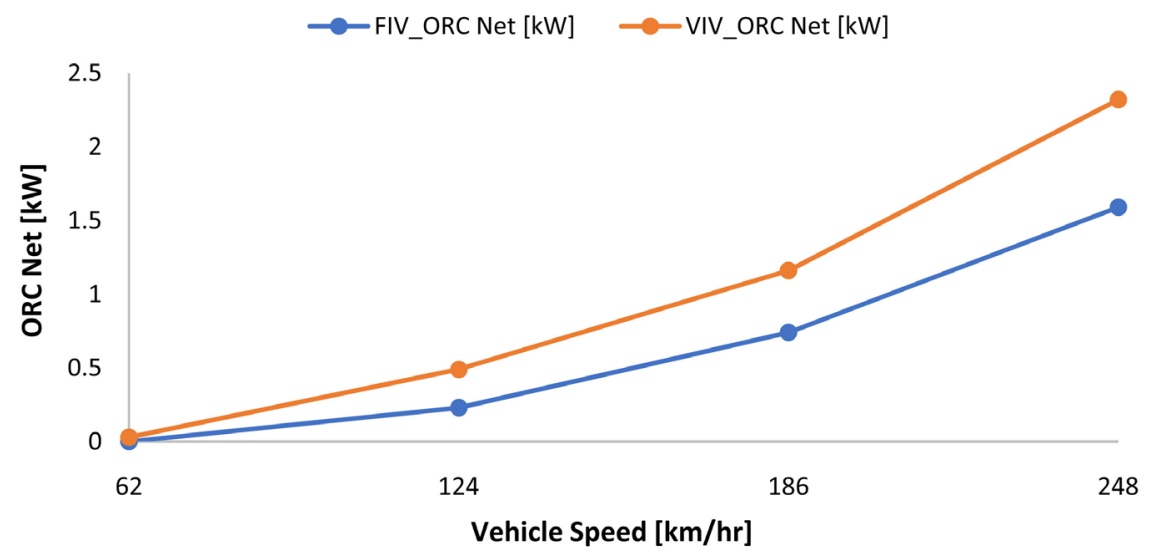

Figure 7. ORC net output. 


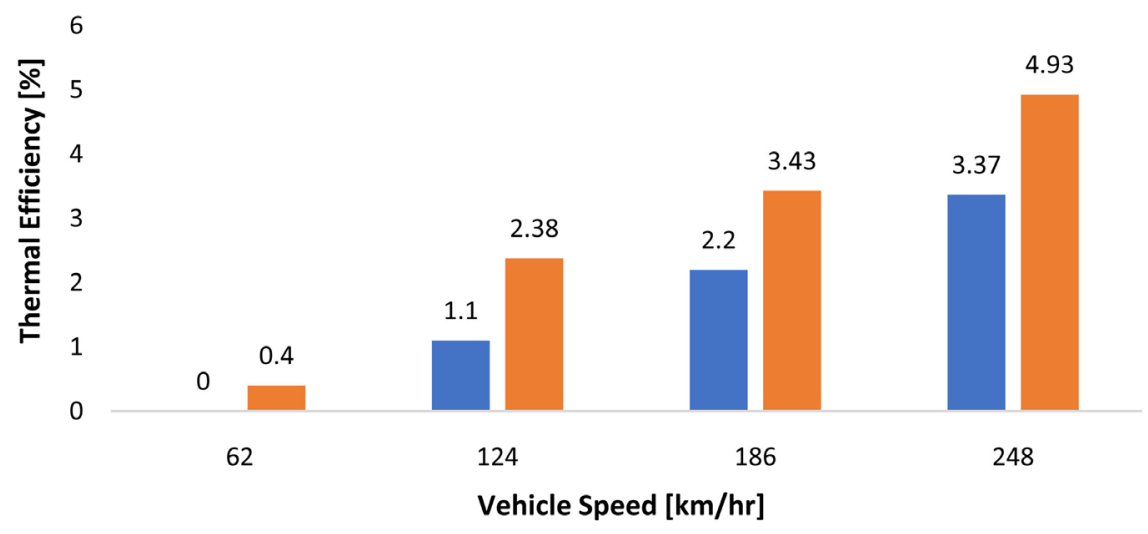

Figure 8. ORC model efficiency.

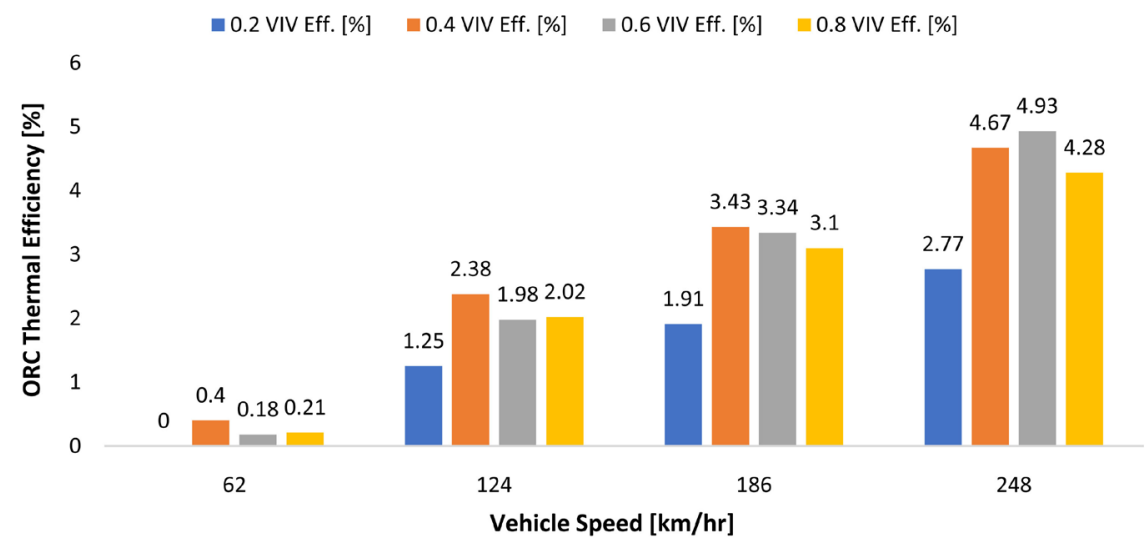

Figure 9. System efficiency achieved at VIV positions.

achieved the optimum averaged value of $2.72 \%$ thermal efficiency, followed by $2.61 \%$ for the structure with 0.6 vanes position, then $2.40 \%$ from the 0.8 vanes position and $1.48 \%$ for 0.2 position.

\section{Conclusion}

In this research, an ORC module with a turbine utilizing VIV configuration was designed for EHR application onboard passenger vehicle with SI engine, and the results compared with that of the ORC unit without a modified guide vanes configuration. The study achieved its primary objective of effectively recovering the thermal exergy in the exhaust stream, which would have exhausted the environment causing pollution and other negative environmental effects. The recovered energy is transformed into electricity to supply electrical power to appliances onboard the passenger vehicle or store in batteries for future use. The comparative findings revealed that the model with modified turbine geometry achieved $2.32 \mathrm{~kW}, 4.93 \%, 6.1 \%$, and $5.0 \%$ for net output, thermal efficiency, mechanical efficiency, and BSFC improvement, as against $1.59 \mathrm{~kW}, 3.37 \%, 4.2 \%$, and $3.7 \%$ for net output, system efficiency, mechanical efficiency, and BSFC improvement, respectively for system without modified turbine geometry. The re- 
sults revealed the huge EHR potentials in employing an ORC system with a VIV turbine configuration in passenger vehicle applications.

\section{Conflicts of Interest}

The authors declare no conflicts of interest regarding the publication of this paper.

\section{References}

[1] Lonza, L. (2020) Determining the Environmental Impacts of Conventional and Alternatively Fuelled Vehicles through LCA: Final Report. Ricardo Energy Environ. https://op.europa.eu/en/publication-detail/-/publication/1f494180-bc0e-11ea-811c01aa75ed71a1

[2] Thaddaeus, J., Unachukwu, G., Mgbemene, C., Mohammed, A. and Pesyridis, A. (2020) Overview of Recent Developments and the Future of Organic Rankine Cycle Applications for Exhaust Energy Recovery in Highway Truck Engines. International Journal of Green Energy, 17, 1005-1021. https://doi.org/10.1080/15435075.2020.1818247

[3] ATRI (American Transportation Research Institute) (2017) US Greenhouse Gas Emissions in the Transportation Sector. http://truckingresearch.org/sustainable-trucking-and-the-environment/\#_ftnref3

[4] ERTRAC. Future Light and Heavy Duty ICE Powertrain Technologies. Ertrac, 1-75. https://www.ertrac.org/index.php?mact=News,cntnt01,detail,0\&cntnt01articleid=39 \&cntnt01returnid $=90$

[5] Freymann, R., Strobl, W. and Obieglo, A. (2008) The Turbosteamer: A System Introducing the Principle of Cogeneration in Automotive Applications. MTZ Worldwide, 69, 20-27. https://doi.org/10.1007/BF03226909

[6] Endo, T., Kawajiri, S., Kojima, Y., Takahashi, K., Baba, T., Ibaraki, S. and Shinohara, M. (2007) Study on Maximizing Exergy in Automotive Engines. SAE Technical Paper Series. https://doi.org/10.4271/2007-01-0257

[7] Rosebro, J. (2008) Honda Researching Advanced Hybrid Drive with Rankine Cycle Co-Generation. https://www.greencarcongress.com/2008/02/honda-researchi/comments/

[8] Zhang, X., Zeng, K., Bai, S., Zhang, Y. and He, M. (2011) Exhaust Recovery of Vehicle Gasoline Engine Based on Organic Rankine Cycle (No. 2011-01-1339). SAE Technical PAPER. https://doi.org/10.4271/2011-01-1339

[9] Freymann, R., Ringler, J., Seifert, M. and Horst, T. (2012) The Second-Generation Turbo-steamer. MTZ Worldwide, 73, 18-23. https://doi.org/10.1365/s38313-012-0138-1

[10] Domingues, A., Santos, H. and Costa, M. (2013) Analysis of Vehicle Exhaust Waste Heat Recovery Potential Using a Rankine Cycle. Energy, 49, 71-85. https://doi.org/10.1016/j.energy.2012.11.001

[11] Horst, T.A., Tegethoff, W., Eilts, P. and Koehler, J. (2014) Prediction of Dynamic Rankine Cycle Waste Heat Recovery Performance and Fuel Saving Potential in Passenger Car Applications Considering Interactions with Vehicles' Energy Management. Energy Conversion and Management, 78, 438-451. https://doi.org/10.1016/j.enconman.2013.10.074

[12] Rosset, K., Mounier, V., Guenat, E., Pajot, O. and Schiffmann, J. (2015) Potential of 
Small-Scale Turbomachinery for Waste Heat Recovery on Automotive Internal Combustion Engines. 3 rd International Seminar on ORC Power Systems, 12, 14.

[13] Cipollone, R., Bianchi, G., Gualtieri, A., Di Battista, D., Mauriello, M. and Fatigati, F. (2015) Development of an Organic Rankine Cycle System for Exhaust Energy Recovery in Internal Combustion Engines. Journal of Physics: Conference Series, 655, Article ID: 012015. https://doi.org/10.1088/1742-6596/655/1/012015

[14] Zhou, F., Dede, E. and Joshi, S. (2016) Application of Rankine Cycle to Passenger Vehicle Waste Heat Recovery-A Review. SAE International Journal of Materials and Manufacturing, 9, 224-235. https://doi.org/10.4271/2016-01-0178

[15] Arsie, I., Cricchio, A., Pianese, C., Ricciardi, V. and De Cesare, M. (2016) Modelling and Optimization of Organic Rankine Cycle for Waste Heat Recovery in Automotive Engines. SAE Technical Paper 2016-01-0207.

https://doi.org/10.4271/2016-01-0207

[16] Shi, R., He, T., Peng, J., Zhang, Y. and Zhuge, W. (2016) System Design and Control for Waste Heat Recovery of Automotive Engines Based on Organic Rankine Cycle. Energy, 102, 276-286. https://doi.org/10.1016/j.energy.2016.02.065

[17] Galindo, J., Dolz, V., Royo-Pascual, L. and Brizard, A. (2017) Dynamic Modeling of an Organic Rankine Cycle to Recover Waste Heat for Transportation Vehicles. Energy Procedia, 129, 192-199. https://doi.org/10.1016/j.egypro.2017.09.111

[18] Pili, R., Romagnoli, A., Spliethoff, H. and Wieland, C. (2017) Economic Feasibility of Organic Rankine Cycles (ORC) in Different Transportation Sectors. Energy Procedia, 105, 1401-1407. https://doi.org/10.1016/j.egypro.2017.03.521

[19] Thaddaeus, J., Unachukwu, G.O., Mgbemene, C.A., Pesyridis, A. and Alshammari, F.A. (2020) Exergy and Economic Assessments of an Organic Rankine Cycle Module Designed for Heat Recovery in Commercial Truck Engines. Indian Journal of Science and Technology, 13, 3871-3883. https://doi.org/10.17485/IJST/v13i37.1299

[20] Andwari, A.M., Pesyridis, A., Karvountzis-Kontakiotis, A. and Esfahanian, V. (2017) Hybrid Electric Vehicle Performance with Organic Rankine Cycle Waste Heat Recovery System. Applied Sciences, 7, 437. https://doi.org/10.3390/app7050437

[21] Zhao, M., Shu, G., Tian, H., Yan, F., Huang, G. and Hu, C. (2017) The Investigation of the Recuperative Organic Rankine Cycle Models for the Waste Heat Recovery on Vehicles. Energy Procedia, 129, 732-739. https://doi.org/10.1016/j.egypro.2017.09.106

[22] Yue, C. and Wang, P. (2019) Thermal Analysis on Vehicle Energy Supplying System Based on Waste Heat Recovery ORC. Energy Procedia, 158, 5587-5595.

https://doi.org/10.1016/j.egypro.2019.01.582

[23] Carstensen, A., Horn, A., Klammer, J. and Gockel, J. (2019) Waste Heat Recovery in Passenger Cars and Trucks. MTZ Worldwide, 80, 50-57. https://doi.org/10.1007/s38313-019-0014-3

[24] Thaddaeus, J., Unachukwu, G.O., Mgbemene, C.A., Pesyridis, A., Usman, M. and Alshammari, F.A. (2021) Design, Size Estimation, and Thermodynamic analysis of a Realisable Organic Rankine Cycle System for Waste Heat Recovery in Commercial Truck Engines. Thermal Science and Engineering Progress, 22, Article ID: 100849. https://doi.org/10.1016/j.tsep.2021.100849

[25] Julius, T., Ibrahim, T.K., Innocent, E.I., Pesyridis, A., Mohammed, A. and Alshammari, F.A. (2021) Steady State Testing of an Organic Rankine Cycle Designed for Exhaust Heat Recovery Applications in Truck Engines. Journal of Sustainable and Green Energy, 10, 7-12. 
[26] Ford Engine Model Specifications. https://www.carfolio.com/ford-fiesta-1.25-302731

[27] RPM to $\mathrm{km} / \mathrm{hr}$ Conversion Formula. https://www.easycalculation.com/formulas/rpm-conversion.html

\section{Nomenclature}

\begin{tabular}{|c|c|}
\hline \multicolumn{2}{|c|}{ Abbreviations } \\
\hline BTE & brake thermal efficiency \\
\hline $\mathrm{CHP}$ & combined heat and power \\
\hline EHR & Exhaust Heat Recovery \\
\hline FIV & fixed inlet guide vanes \\
\hline GHG & Greenhouse gas \\
\hline GWP & global warming potentials \\
\hline ICE & internal combustion engine \\
\hline NEDC & new European driving cycle \\
\hline ORC & organic Rankine cycle \\
\hline PEMFC & Proton Exchange Membrane Fuel Cell \\
\hline $\mathrm{PM}$ & particulate matter \\
\hline $\mathrm{R} \& \mathrm{D}$ & research and development \\
\hline rpm & revolution per minute \\
\hline SI & spark ignition \\
\hline T-s & temperature-entropy \\
\hline UK & United Kingdom \\
\hline US & United States of America \\
\hline VIV & variable inlet guide vanes \\
\hline WF & Working fluid \\
\hline WHR & Waste heat recovery \\
\hline \multicolumn{2}{|c|}{ Greek symbols } \\
\hline$\dot{m}_{r}$ & Mass flow rate $[\mathrm{kg} / \mathrm{s}]$ \\
\hline$\dot{W}$ & Work done $[\mathrm{kW}]$ \\
\hline$h$ & Enthalpy $[\mathrm{kJ} / \mathrm{kg}]$ \\
\hline$\eta$ & Efficiency [\%] \\
\hline$\dot{Q}$ & Thermal power $[\mathrm{kW}]$ \\
\hline$\rho$ & Density $\left[\mathrm{kg} / \mathrm{m}^{3}\right]$ \\
\hline$\omega$ & Speed $[\mathrm{rad} / \mathrm{s}]$ \\
\hline \multicolumn{2}{|c|}{ Subscripts } \\
\hline in & Inlet \\
\hline mech & Mechanical \\
\hline out & Outlet \\
\hline th & Thermodynamic \\
\hline turb & Turbine \\
\hline
\end{tabular}

